\title{
Nucleus-cytoplasm interactions causing reproductive incompatibility between two populations of Tetranychus quercivorus Ehara et Gotoh (Acari: Tetranychidae)
}

\author{
TETSUO GOTOH*, HIROYUKI OKU, KAZUAKI MORIYA \& MASANORI ODAWARA \\ Laboratory of Applied Entomology and Zoology, Faculty of Agriculture, Ibaraki University, Ami, Ibaraki 300-03, Japan
}

\begin{abstract}
Partial reproductive incompatibility between two local populations of Tetranychus quercivorus Ehara et Gotoh derived from Sapporo $\left(43^{\circ} \mathrm{N}\right)$ and Tsukuba $\left(36^{\circ} \mathrm{N}\right)$, Japan, was found. The incompatibility was unidirectional: the Sapporo female was incompatible with the Tsukuba males, which resulted in a low egg hatchability and strongly male-biased sex ratio, whereas the reciprocal cross was compatible and produced normal progeny with a female-biased sex ratio. To determine the genetic mechanism responsible for the incompatibility, crosses were made between the two populations over five to six filial generations as well as backcrosses. The results suggested that the incompatibility could be caused by an interaction between the cytoplasm from the Sapporo population and a single nuclear gene from the Tsukuba population. Compatibility was not restored when individuals of the Sapporo population were treated with antibiotics or high temperature, indicating a possibility that the cytoplasmic factors are cytoplasmically inherited elements such as mitochondria rather than microorganisms.
\end{abstract}

Keywords: Acari, cytoplasm, nucleus, population genetics, reproductive incompatibility, Tetranychus quercivorus.

\section{Introduction}

Partial reproductive incompatibility between conspecific strains originating from different geographical localities has been reported in many insects and other arthropods such as mites (Oliver, 1979; De Boer, 1982; Thompson, 1987; Stevens \& Wade, 1990; Rousset \& Raymond, 1991; Bressac \& Rousset, 1993; Gotoh et al., 1993). There are unidirectional and bidirectional incompatibilities (Breeuwer \& Werren, 1993). In the former, a failure to hatch occurs in a cross between two populations, whereas the reciprocal cross is compatible and produces normal progeny. When incompatibility is bidirectional, on the other hand, both reciprocal crosses are incompatible and no fertile eggs develop. In most cases, the causative agent for the unidirectional incompatibility is maternally inherited microorganisms such as Wolbachia, and incompatibility can occur in crosses between bacteria-infected males and uninfected females (Ehrman, 1983; Hsiao \& Hsiao, 1985; Wade \& Stevens, 1985; Hoffmann, 1988; Stevens \& Wicklow, 1992; Ebbert, 1993). Incompatibility may be cured with antibiotics or high tempera-

*Correspondence. ture treatment (Trpis et al., 1981; Wade \& Stevens, 1985; Hoffmann et al., 1986; Richardson et al., 1987; Stevens, 1989).

Genetic incompatibility is also found in spider mites. Hybrids obtained from a cross between different populations of Tetranychus urticae Koch develop to adulthood, but most eggs deposited by the hybrid females fail to hatch in unidirectional crosses (Overmeer \& van Zon, 1976; De Boer, 1982, 1983). Fry (1989) argues that incompatibility of $T$. urticae is mainly the result of nuclear-cytoplasmic interactions and sometimes of lethal recombinations of genes, although a cytoplasmic element causing incompatibility has not been identified yet.

In another spider mite, Tetranychus quercivorus Ehara et Gotoh (formerly Tetranychus viennensis Zacher), unidirectional incompatibility has been observed in a cross between two local populations derived from Sapporo $\left(43^{\circ} \mathbf{N}\right)$ and Tsukuba $\left(36^{\circ} \mathbf{N}\right)$, Japan (Gotoh \& Takayama, 1992). A cross between females from Tsukuba and males from Sapporo gives a high rate of egg hatchability and a female-biased sex ratio, but the reciprocal cross results in a much lower hatchability and a male-biased sex ratio. However, the mechanism causing this phenomenon has not been 
studied in this species. The purpose of the present study was to analyse the genetic mechanism responsible for the reproductive incompatibility between the two local populations of $T$. quercivorus, and to discuss the possible causative agent of the incompatibility. In this study, we carried out crossing experiments between the Sapporo and Tsukuba populations, and then tested if the factor causing the incompatibility could be suppressed by antibiotics or heat.

\section{Materials and methods}

\section{Mites}

Mites were collected from the deciduous oak, Quercus mongolica var. grosseserrata (Blume), in Sapporo and Tsukuba in June and May 1991, respectively. Each population was separately maintained on leaf discs $(c$. $25 \mathrm{~cm}^{2}$ ) of the hosts placed on wet cotton in petri dishes $(9 \mathrm{~cm}$ diameter) at a $16 \mathrm{~L}-8 \mathrm{D}$ photoperiod, 60-70 per cent $\mathrm{R} \mathrm{H}$ and $25 \pm 1^{\circ} \mathrm{C}$. All experiments were carried out under the same conditions except for experiments to test the effect of high temperature.

\section{Crossing}

Crosses between the Sapporo and Tsukuba populations were made to confirm their reproductive incompatibility. Females in the teleiochrysalis stage were obtained from each stock culture and each female was transferred onto a small leaf disc $\left(c .4 \mathrm{~cm}^{2}\right)$ with a male adult from the same or the other population. The males were removed 2 days after adult emergence of the females. After oviposition started, each female was allowed to lay eggs for 5 days and then removed. Eggs on leaf discs were checked every day to determine the hatchability, survival rate and sex ratio. If females died within 5 days of oviposition or moved to other leaf discs during oviposition, the replicate was discarded. Data were analysed by one-way analysis of variance (ANOVA) and means were tested by Duncan's multiple range test. The arcsin-transformed values were used for analysing percentage hatchability, survival rate and sex ratio.

To determine how incompatibility is brought about through filial generations, four series of crosses of progeny obtained from the above crosses were carried out except for the cross between the Sapporo females and Tsukuba males (abb. Sapporo $\odot \times$ Tsukuba $\left.\sigma^{\prime}\right)$. In the Sapporo $\odot \times$ Tsukuba $\sigma^{\prime}$ cross, female offspring were extremely few and thus another set of crosses was made to obtain females originating from the incompatible pairs. The first series was started with progeny of the Sapporo $\$ \times$ Tsukuba 0 cross. Crosses were made over five filial generations (Fig. 1). In each generation, the progenies were also mated with either Tsukuba males, Sapporo males, Tsukuba females or Sapporo females. The number of pairs tested for each cross was 51.4 on average with a range from 23 to 118 .

Basically the same type of crossing was made in a second series except that this series was started with progenies of the Tsukuba $\% \times$ Sapporo of cross (Fig. 2). The average number of pairs used in each cross was 63.7, ranging from 41 to 118 .

To determine if chromosomal factors are involved in the inheritance of incompatibility, females that had the genome of the Sapporo population and the cytoplasm of the Tsukuba population were produced and their compatibility was tested in a third series of crosses. That is, offspring of the Tsukuba $\odot \times$ Sapporo $\sigma^{\circ}$ cross were backcrossed with Sapporo males for five generations and other offspring of each generation were crossed with either male progeny of the same brood, Tsukuba males, Tsukuba females or Sapporo females (Fig. 3). The number of pairs tested was 28.9 on average, ranging from 13 to 101 .

The last experiment investigated the effect of the genome from the Tsukuba population on the occurrence of incompatible pairs. Males produced by $F_{1}$ virgin females derived from the Tsukuba $\% \times$ Sapporo on cross were crossed with Sapporo females. The same procedure was followed for the next generation, i.e. males produced by $F_{2}$ virgin females from the cross, $\left(\left(\right.\right.$ Tsukuba $\% \times$ Sapporo $\left.\sigma^{\prime \prime}\right) \% \times$ Tsukuba $\left.0^{\prime}\right)$, were crossed with Sapporo females (Fig. 4). In these crosses, the percentage of males with the genome of the Tsukuba population was expected to be 50 per cent and 75 per cent in the $F_{1}$ and $F_{2}$ generations, respectively.

\section{Antibiotic treatment}

To test if the incompatibility is caused by cytoplasmically inherited microorganisms, mites of the Sapporo population were treated with various antibiotics. Small leaf discs $\left(c .0 .25 \mathrm{~cm}^{2}\right)$ were placed side by side on a cotton bed soaked in antibiotic solution in petri dishes ( $9 \mathrm{~cm}$ in diameter), and $24 \mathrm{~h}$ later newly hatched larvae, which were obtained from the stock culture, were transferred onto the leaf discs. Distilled water was added every day to keep the cotton beds wet, and the cotton as well as the leaf discs were renewed every 5 days. Mites were treated with antibiotics for one to three generations. Females obtained were crossed with males of the Tsukuba population, and their compatibility was observed. The same procedure was followed for male larvae of the Tsukuba population. These males 




Fig. 1 Crossings among progeny obtained from the cross between the Sapporo(S) females and the Tsukuba $(\mathrm{T})$ males, and crossings between parents and progeny. $F_{x}$ means individuals of $F_{1}, F_{2}, F_{3}, F_{4}$ or $F_{5}$ used for crossing. In every combination, the black and dark hatched parts in circles represent percentages of incompatible pairs. The outer and central circles in a double circle show the proportions of incompatible pairs observed and expected, respectively. Symbols put under a double circle show the crossing code. $\chi^{2}$-test and Fisher's exact probability test were used for analysis (observed vs. expected; $* * P<0.01 ;$ ns, not significant).

were paired with females of the Sapporo population. In our preliminary tests, we examined whether or not antibiotics were taken up by mites by providing larvae with pieces of leaf that had been exposed to a mixture of antibiotics and food colour for $24 \mathrm{~h}$. Such larvae became slightly pigmented after feeding and juvenile mortality occurred depending upon the concentration of the antibiotics. Therefore, the antibiotics applied appeared to be taken up by the mites.

\section{Heat treatment}

To examine whether or not the compatibility in the Sapporo $\% \times$ Tsukuba of cross can be restored by heat, larvae of the Sapporo population were transferred onto the leaf discs $\left(c .30 \mathrm{~cm}^{2}\right)$ and kept at $30^{\circ} \mathrm{C}$ for one to three generations. Female adults emerging at each generation were crossed with males of the Tsukuba population, and the number of females in the $F_{1}$ generation was counted. Similar observations were made for newly emerged female adults after an exposure to a temperature of 45,50 or $60^{\circ} \mathrm{C}$ for several minutes.

\section{Results}

\section{Crosses between the Sapporo and Tsukuba populations}

Table 1 gives the results of crosses between the Sapporo and Tsukuba populations of T. quercivorus. In the intrapopulation crosses, hatchability of eggs was 


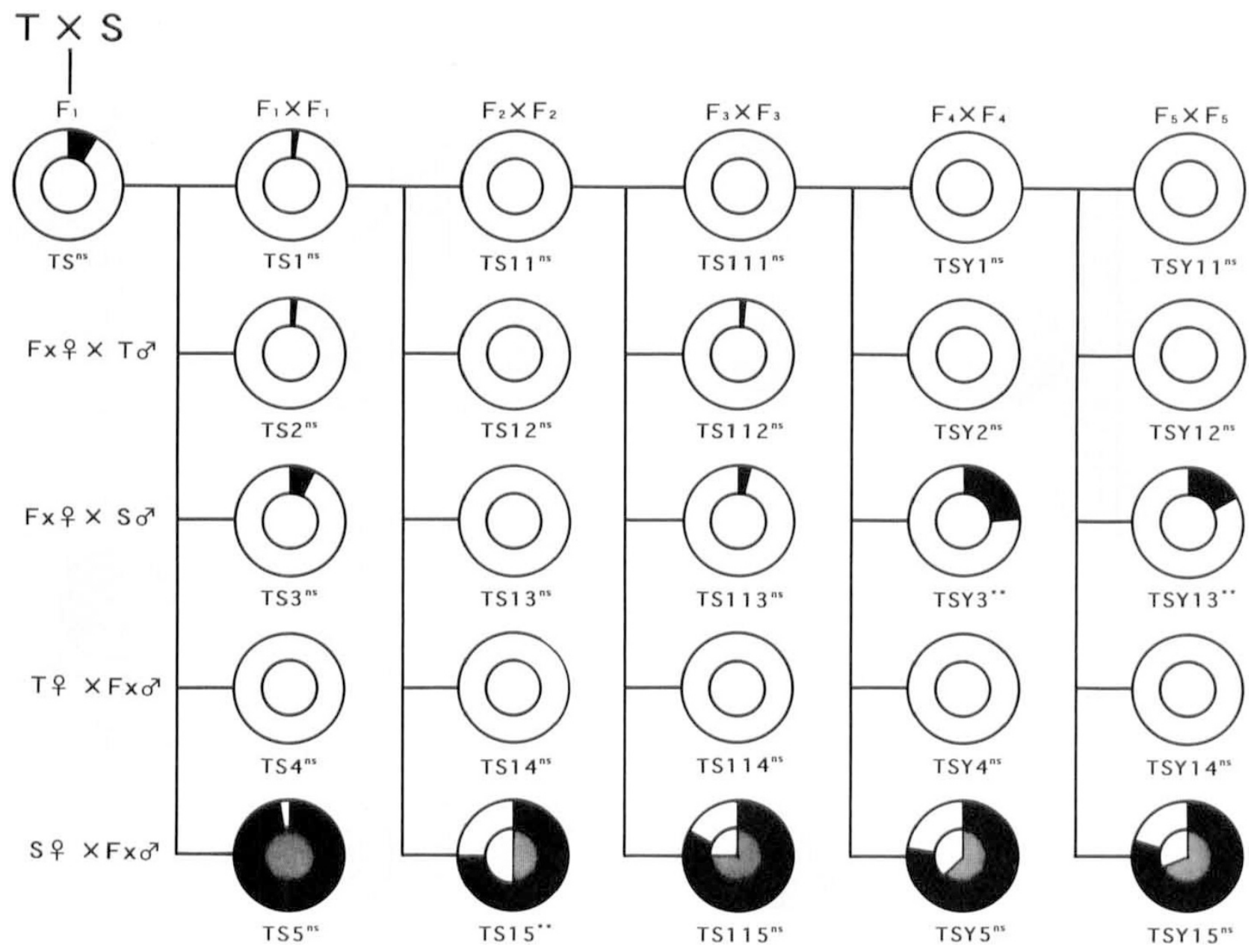

Fig. 2 Crossings among progeny obtained from the cross between the Tsukuba females and the Sapporo males, and crossings between parents and progeny. See also Fig. 1 for details.

greater than 97 per cent on average with a range from 76.2 per cent to 100 per cent, and more than 83 per cent, ranging from 65.1 to 100 per cent, of the hatchlings that attained maturity were females. The survival rate of juvenile stages was similar in these crosses.

In the cross involving Tsukuba females and Sapporo males, nine out of 101 pairs produced eggs with a lower egg hatchability, and the survival rate of the juveniles was lower compared with the value in the intrapopulation cross (Table 1). The reciprocal cross was less successful: only five out of 129 pairs produced a few female offspring ( 24 females in total) and the others none. This particular cross showed an extremely low hatchability and a male-biased sex ratio, but the survival rate of juveniles was similar to that in the intrapopulation cross. The virgin females from the Tsukuba and Sapporo populations produced a slightly smaller number of eggs than did the mated females (Table 1). Hatchability and survival rate of juvenile stages were as high as those of females crossed with males from the same population, although no female progeny appeared. This shows that T. quercivorus is arrhenotokous where females are diploid but males develop from unfertilized eggs.

Based on the results given above, when hatchability was $>76$ per cent and the proportion of female adults obtained was $>65$ per cent (the values corresponding to the minimal rates obtained from the intrapopulation cross), we regarded the pair as compatible.

\section{Crosses in filial generations}

In the crossing series of the Sapporo $\& \times$ Tsukuba 0 progeny, incompatible pairs appeared in 14 out of 22 crossings (Fig. 1), whereas in the Tsukuba $\% \times$ Sapporo o series, 13 out of 26 crossings yielded incompatible pairs (Fig. 2). Based on these results, especially on the crossings of ST, ST2, ST3, ST15, TS and TS3, we 


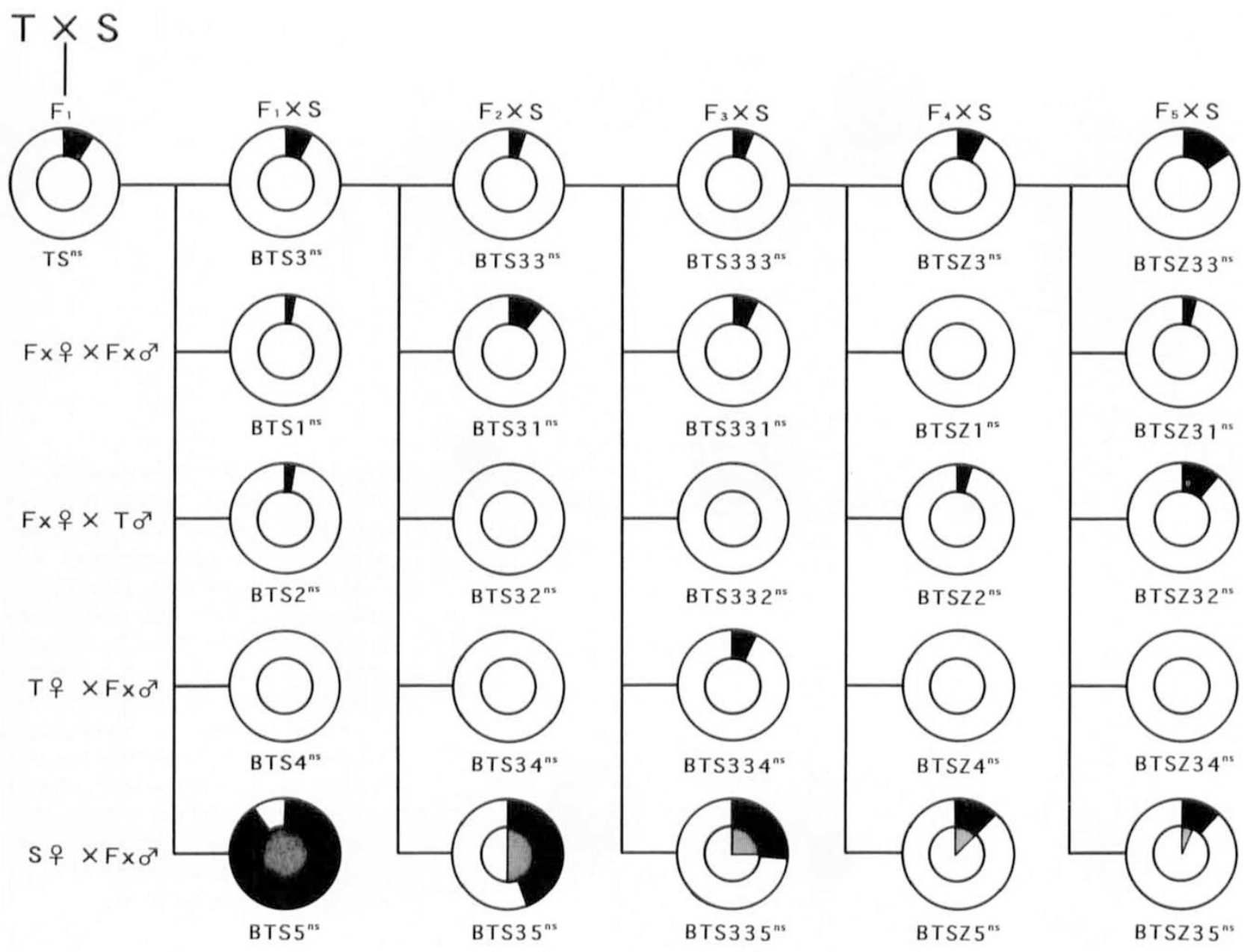

Fig. 3 Backcrossings between the Sapporo males and the female offspring obtained from the cross involving Tsukuba females and Sapporo males, and crossings between parents and offspring. See also Fig. 1 for details.

supposed that the reproductive incompatibility of $T$. quercivorus could be due to interactions between the egg cytoplasm of the Sapporo population and the sperm nucleus of the Tsukuba population. We assumed that a single nuclear gene was responsible for incompatibility.

To test this hypothesis, the percentage of incompatible pairs expected from both the frequency of nuclear genes derived from the Tsukuba population and the existence of cytoplasm of the Sapporo population was calculated. The expected values are shown in Figs 1 and 2 , and they were analysed by the $\chi^{2}$-test or Fisher's exact probability test. In the Sapporo $\& \times$ Tsukuba $\sigma^{*}$ series, the percentages of incompatible pairs observed corresponded to the expected values in all cases except for seven crossings, i.e. ST11, ST111, STY1, STY11, ST12, ST112 and STY2, in which the observed values were lower than expected (Fig. 1). Because the Sapporo $\& \times$ Tsukuba $\delta$ cross produced only a few viable females, it seemed possible that such females had relatively small amounts of a cytoplasmic factor(s) causing the incompatibility. This may explain the unexpected results obtained in the above seven crossings. In the Tsukuba $\% \times$ Sapporo $\sigma$ series, the observed values also corresponded well to the expected values, although a few cases including TSY3, TSY13 and TS15 showed a higher value than expected (Fig. 2). The inconsistency in these exceptional cases was probably because of the relatively small number of pairs used in each crossing (41-91). As will be shown later, we obtained a value close to the expected one in the cross TS15 when the number of pairs tested was increased from 91 to 493 (cf. Fig. 4).

\section{Backcross experiment}

Assuming a single nuclear gene, the proposed mechanism for incompatibility in $T$. quercivorus predicts that 

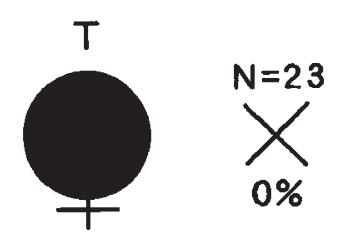

S

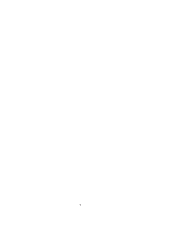

0


$3.0 \%$<smiles>CCCCC=CC=CC=S</smiles>

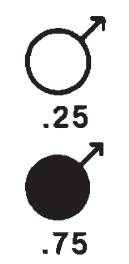

$\frac{N=33}{\substack{\text { Virgin } \\ \text { females }}}$

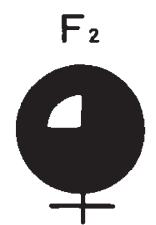

T



Fig. 4 Interactions between male nucleus and female cytoplasm. In every combination, the solid and open parts in circles represent the nature of Tsukuba and Sapporo populations, respectively. The central and outer circles in a double circle for females show the nucleus and cytoplasm, respectively, and circles for males represent the nucleus only. Values put under male symbols show the expected ratios of nuclear types. Percentages drawn under crosses indicate the percentages of incompatible pairs observed. $\chi^{2}$-test was used for analysis (observed vs. expected; ns, not significant).

Table 1 Number of eggs laid during the first 5 days of oviposition, hatchability, survival rate in juvenile stages and sex ratio of the $F_{1}$ progeny from crosses between the Sapporo and Tsukuba populations of Tetranychus quercivorus $\dagger$

\begin{tabular}{lrcccc}
\hline \multicolumn{1}{c}{ Cross } & & & & & \\
\cline { 1 - 3 } Female $\times$ male & $N \neq$ & $\begin{array}{r}\text { Total no. of } \\
\text { eggs/female }\end{array}$ & $\begin{array}{c}\text { Hatchability } \\
(\%)\end{array}$ & $\begin{array}{c}\text { Survival } \\
\text { rate }(\%)\end{array}$ & $\begin{array}{c}\text { Sex ratio } \\
(\% \text { females })\end{array}$ \\
\hline Sapporo Sapporo & 64 & $16.6 \pm 0.42 \mathrm{~b}$ & $98.1 \pm 0.50 \mathrm{a}$ & $93.9 \pm 0.82 \mathrm{a}$ & $83.9 \pm 0.85 \mathrm{a}$ \\
Tsukuba Tsukuba & 62 & $19.0 \pm 0.45 \mathrm{a}$ & $97.0 \pm 0.50 \mathrm{ab}$ & $95.3 \pm 0.75 \mathrm{a}$ & $83.5 \pm 0.67 \mathrm{a}$ \\
Tsukuba Sapporo & 101 & $18.6 \pm 0.48 \mathrm{a}$ & $91.1 \pm 1.24 \mathrm{c}$ & $89.1 \pm 1.02 \mathrm{~b}$ & $81.1 \pm 1.15 \mathrm{a}$ \\
Sapporo Tsukuba & 129 & $16.8 \pm 0.38 \mathrm{~b}$ & $20.9 \pm 1.01 \mathrm{~d}$ & $92.0 \pm 1.28 \mathrm{a}$ & $1.7 \pm 0.84 \mathrm{~b}$ \\
Tsukuba§ & 59 & $13.8 \pm 0.39 \mathrm{c}$ & $96.0 \pm 0.77 \mathrm{ab}$ & $92.0 \pm 1.02 \mathrm{ab}$ & 0 \\
Sapporo & 47 & $13.5 \pm 0.39 \mathrm{c}$ & $95.0 \pm 0.99 \mathrm{~b}$ & $94.0 \pm 1.10 \mathrm{a}$ & 0 \\
F-ratio & & $22.81^{* *}$ & $660.11^{* *}$ & $6.31^{* *}$ & $1784.94^{* *}$ \\
\hline
\end{tabular}

**Means differed significantly at $P<0.01$ (one-way analysis of variance, ANOVA).

$\dagger$ Means \pm SEM in a column followed by different letters are significantly different at $P<0.05$ (Duncan's multiple range test).

$\ddagger$ All pairs tested produced eggs.

$\S$ Females were kept virgin. 
the percentage of incompatible pairs in the backcross experiment should decrease with the progress of generations, because the frequency of a nuclear gene derived from the Tsukuba population will be gradually reduced with repeated backcrossing to the Sapporo males. The hypothesis also predicts that the incompatible pairs should appear only in the cross between the Sapporo females and hybrid males. These predictions were confirmed by the results obtained from the backcross experiment, i.e. the observed values corresponded well to the expected values without any exception (Fig. 3).

\section{Interactions between male nucleus and female cytoplasm}

To examine further the nuclear-cytoplasmic interactions, males produced by virgin females, which were obtained from the Tsukuba $\% \times$ Sapporo $\delta$ cross, were mated with the Sapporo females. In this crossing, it was expected that 50 per cent of the pairs tested would be incompatible. Furthermore, when males were produced by $F_{2}$ virgin females originating from the

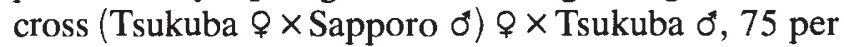
cent were expected to be incompatible. As shown in Fig. 4, the results were very close to the expected values.

These results strongly suggest that the unidirectional reproductive incompatibility in $T$. quercivorus is caused by an interaction between the egg cytoplasm of the Sapporo population and the sperm nucleus of the Tsukuba population.

\section{Antibiotic treatment}

To determine if the causative agent in the female cytoplasm is a microorganism, mites were exposed to 12 kinds of antibiotics. All antibiotics tested had no effect on the incompatibility displayed by the Sapporo $\$ \times$ Tsukuba o cross (Table 2). To examine the effect of antibiotics on males, male larvae produced by virgin Tsukuba females were treated with three kinds of antibiotics, and upon adult emergence they were allowed to mate with females of the Sapporo population. Drug treatment of the Tsukuba males was not effective in restoring the compatibility of the two populations (Table 2).

\section{Heat treatment}

Raising the Sapporo population at $30^{\circ} \mathrm{C}$ for up to three filial generations did not affect the incompatibility in the subsequent cross with males of the Tsukuba population (Table 3). In the Sapporo females raised at higher temperatures of 45,50 and $60^{\circ} \mathrm{C}$, there was no significant difference in percentage of pairs yielding female progeny between the treated and untreated females (Table 3). These results, together with those of antibiotic treatment, did not provide positive evidence for the involvement of a cytoplasmic microorganism in the incompatibility between the two populations.

\section{Discussion}

The present results indicate that the low hatchability and male-biased sex ratio in the Sapporo $\odot \times$ Tsukuba $\delta$ cross are due to the high mortality of fertilized eggs destined to become females. This is consistent with the conclusion by Gotoh \& Takayama (1992) who studied the same species under the name of a deciduous oak strain of $T$. viennensis. The lethal character of incompatibility in the species appears only in female progenies. This is because females possess chromosomes originating from both maternal and paternal parents, while males have only maternal chromosomes, as pointed out by Ebbert (1993).

Interpopulation incompatibility is expressed more strongly in $T$. quercivorus than in T. urticae (Overmeer \& van Zon, 1976; De Boer, 1982, 1983), and the timing of death in the hybrids differs between the two species. Death occurs in the $F_{1}$ generation in $T$. quercivorus, while it occurs in the $\mathrm{F}_{2}$ generation in $T$. urticae. Egg mortality is observed in both haploid and diploid eggs in T. urticae (De Boer, 1982), but only in diploid eggs in $T$. quercivorus. Thus, the mode of incompatibility in T. quercivorus is different from that in T. urticae.

The most significant finding in the current study is that unidirectional incompatibility between two local populations of $T$. quercivorus could be caused by an interaction between the egg cytoplasm of one population and the sperm nucleus of the other, although there is a discordance between the observed and expected results in some cases.

A cytoplasmic element in insects is a maternally inherited microorganism (Ebbert, 1993), and treatment of infected individuals with antibiotics or high temperature can sometimes restore the compatibility (Trpis et al., 1981; Hoffmann et al., 1986; Hoffmann \& Turelli, 1988; Stevens, 1989). In T. quercivorus, compatibility was not restored when individuals of the Sapporo population were treated with antibiotics or high temperature. This indicates that the cytoplasmic factor responsible for the incompatibility in this species may be cytoplasmically heritable agents such as mitochondria and the strain-specific RNA (Laven, 1967; Breeuwer \& Werren, 1993), rather than microorganisms.

Incompatibility associated with cytoplasmic microorganisms is transmitted over successive generations of outcrosses, because microorganisms are preserved in 
Table 2 Effects of antibiotics on an incompatible cross, Sapporo $(\mathrm{S}) \propto \times$ Tsukuba (T) o", in Tetranychus quercivorus

\begin{tabular}{|c|c|c|c|c|c|c|}
\hline \multirow[b]{2}{*}{ Antibiotics } & \multirow{2}{*}{$\begin{array}{l}\text { Concentration } \\
(\mathrm{w} / \mathrm{v} \%)\end{array}$} & \multicolumn{3}{|c|}{ Treatment } & \multirow{2}{*}{$\begin{array}{c}\% \text { Females } \\
\text { yielding } \\
\text { female progeny } \dagger\end{array}$} & \multirow[b]{2}{*}{$P \ddagger$} \\
\hline & & Sex & Duration $(G)^{*}$ & $N$ & & \\
\hline \multirow[t]{2}{*}{ Penicillin G } & 0.01 & Sㅇ & 2 & 57 & 10.5 & 0.19 \\
\hline & 0.1 & & 2 & 73 & 6.8 & 1.78 \\
\hline \multirow[t]{2}{*}{ Ampicillin } & 0.01 & S\& & 2 & 40 & 0.0 & 0.53 \\
\hline & 0.1 & & 2 & 90 & 1.1 & 0.45 \\
\hline \multirow[t]{2}{*}{ Polymyxin B } & 0.01 & $\mathrm{~S} \wp$ & 2 & 24 & 12.5 & 1.94 \\
\hline & 0.1 & & 3 & 62 & 1.6 & 0.75 \\
\hline \multirow[t]{2}{*}{ Streptomycin } & 0.01 & $\mathbf{S} \subsetneq$ & 2 & 64 & 4.7 & 1.49 \\
\hline & 0.1 & & 3 & 64 & 3.1 & 1.16 \\
\hline \multirow[t]{2}{*}{ Kanamycin } & 0.01 & $\mathrm{~S} \wp$ & 2 & 59 & 3.4 & 1.24 \\
\hline & 0.1 & & 2 & 82 & 6.1 & 1.70 \\
\hline \multirow{3}{*}{$\begin{array}{l}\text { Tetracycline } \\
\text { hydrochloride }\end{array}$} & 0.01 & $\mathrm{~S} \wp$ & 2 & 94 & 2.1 & 0.76 \\
\hline & 0.1 & & 2 & 246 & 8.9 & 0.13 \\
\hline & 0.5 & & 1 & 97 & 2.1 & 0.73 \\
\hline \multirow{4}{*}{$\begin{array}{l}\text { Oxytetracycline } \\
\text { hydrochloride } \\
\text { Erythromycin }\end{array}$} & 0.01 & $\mathrm{~S}$ ㅇ & 2 & 86 & 5.8 & 1.66 \\
\hline & 0.1 & & 1 & 57 & 0.0 & 0.33 \\
\hline & 0.01 & $\mathrm{~S} \wp$ & 1 & 123 & 5.7 & 0.73 \\
\hline & 0.1 & & 2 & 157 & 6.4 & 0.54 \\
\hline \multirow[t]{2}{*}{ Nystatin } & 0.01 & $\mathrm{~S} \wp$ & 2 & 52 & 7.7 & 1.83 \\
\hline & 0.1 & & 2 & 55 & 9.1 & 1.90 \\
\hline \multirow[t]{3}{*}{ Chloramphenicol } & 0.01 & S & 3 & 115 & 1.7 & 0.57 \\
\hline & 0.1 & & 1 & 154 & 4.5 & 1.03 \\
\hline & 0.5 & & 1 & 32 & 3.1 & 1.32 \\
\hline \multirow[t]{2}{*}{ Rifampicin } & 0.01 & $\mathrm{~S} \wp$ & 2 & 116 & 4.3 & 1.37 \\
\hline & 0.1 & & 1 & 119 & 1.7 & 0.53 \\
\hline \multirow[t]{2}{*}{ Nalidixic acid } & 0.01 & $\mathrm{~S} \wp$ & 2 & 63 & 6.3 & 1.72 \\
\hline & 0.1 & & 2 & 95 & 2.1 & 0.75 \\
\hline \multirow{4}{*}{$\begin{array}{l}\text { Tetracycline } \\
\text { hydrochloride } \\
\text { Erythromycin }\end{array}$} & 0.01 & Tơ & 1 & 96 & 3.1 & 1.07 \\
\hline & 0.1 & & 1 & 57 & 3.5 & 1.27 \\
\hline & 0.01 & Tơ & 1 & 33 & 15.2 & 1.98 \\
\hline & 0.1 & & 1 & 61 & 3.3 & 1.20 \\
\hline \multirow[t]{2}{*}{ Chloramphenicol } & 0.01 & Tơ & 1 & 60 & 1.7 & 0.78 \\
\hline & 0.1 & & 1 & 30 & 3.3 & 1.37 \\
\hline Control & - & - & - & 129 & 3.9 & \\
\hline
\end{tabular}

${ }^{*} \mathrm{G}$ means generation. See text for details.

$\nmid$ Pairs which yielded one or more female progeny were calculated.

$\ddagger$ Fisher’s exact probability test (control vs. treatment).

progeny without any dilution (Noda, 1984; Rousset \& Raymond, 1991). However, the expression of incompatibility in $T$. quercivorus follows the theoretical gene ratio from the Tsukuba population (Figs 3 and 4 ), suggesting that a nuclear gene appears to be highly specific with respect to the cytoplasmic element(s). This is a conspicuous difference from the microorganism-mediated cytoplasmic incompatibility. Examples of incompatibility between the cytoplasmic factors of one population and the nuclear genes of another population are known in insects (Thompson, 1987) and plants such as wheat (Toriyama et al., 1993) and cybrid plants possessing the Atropa genome and
Nicotiana plastome (Kushnir et al., 1991). In wheat, the $\mathrm{S}^{\mathrm{V}}$ type cytoplasm induces male sterility only in cultivars that do not have the fertility-restoring gene $R f v I$ (Toriyama et al., 1993). As in wheat, the unidirectional incompatibility in $T$. quercivorus may be explained as follows. The single nuclear gene, $T^{\mathrm{i}}$, from a $\mathrm{T}$ strain such as the Tsukuba population activates only the $S$ type cytoplasm from the $S$ strain such as the Sapporo population. Consequently, only the fertilized eggs which have the specific gene die, while those which have not give normal development against the $S$ type cytoplasm. 
Table 3 Effect of high temperature on an incompatible cross, Sapporo (S)

$\$ \times$ Tsukuba (T) o , in Tetranychus quercivorus

\begin{tabular}{|c|c|c|c|c|c|}
\hline \multirow[b]{2}{*}{ Temperature } & \multicolumn{3}{|c|}{ Treatment } & \multirow{2}{*}{$\begin{array}{c}\% \text { Females } \\
\text { yielding } \\
\text { female progeny } \dagger\end{array}$} & \multirow[b]{2}{*}{$P \ddagger$} \\
\hline & Sex & $\begin{array}{l}\text { Duration } \\
(\mathrm{G} \text { or } \mathrm{min})^{*}\end{array}$ & $N$ & & \\
\hline \multirow{3}{*}{$30^{\circ} \mathrm{C}$} & Sㅇ & $1 \mathrm{G}$ & 63 & 6.3 & 1.72 \\
\hline & & $2 \mathrm{G}$ & 28 & 3.6 & 1.42 \\
\hline & & $3 \mathrm{G}$ & 60 & 3.3 & 1.22 \\
\hline $45^{\circ} \mathrm{C}$ & Sq & $10 \mathrm{~min}$ & 119 & 2.5 & 0.83 \\
\hline $50^{\circ} \mathrm{C}$ & So & $10 \mathrm{~min}$ & 91 & 5.5 & 1.62 \\
\hline $60^{\circ} \mathrm{C}$ & So & $2 \min$ & 108 & 6.5 & 0.57 \\
\hline $25^{\circ} \mathrm{C}$ (control) & - & - & 129 & 3.9 & \\
\hline
\end{tabular}

${ }^{*} \mathrm{G}$ means generation. See text for details.

$\dagger$ Pairs which yielded one or more female progeny were calculated.

‡Fisher's exact probability test (control vs. treatment).

Although the details of the cytoplasmic factor and specific gene are unidentified, the outcome of interaction between the cytoplasmic factor and the nuclear gene could potentially lead to reproductive isolation among different populations involving different types of cytoplasm. If so, this incompatibility is of interest from a genetic point of view and may provide an ideal system to study the mechanism of speciation. Further research is required to clarify how common this incompatibility is in populations of this species and at which embryonic stage eggs laid by incompatible pairs die.

\section{Acknowledgements}

We feel indebted to Dr S. Tanaka, National Institute of Sericultural and Entomological Science, for numerous comments that greatly improved the manuscript, to $\mathrm{Dr}$ R. De Boer, Amsterdam University, for his valuable suggestions that led to the analysis of incompatibility, and to Mr M. Kakizaki, Hokkaido Central Agricultural Experiment Station, for collecting spider mites. The Tsukuba population of $T$. quercivorus was collected with permission in the Tsukuba Botanical Garden, National Science Museum.

\section{References}

BREEUWER, J. A. J. AND WERREN, J. H. 1993. Effect of genotype on cytoplasmic incompatibility between two species of Nasonia. Heredity, 70, 428-436.

BRESSAC, C. AND ROUSSET, F. 1993. The reproductive incompatibility system in Drosophila simulans: Dapi-staining analysis of the Wolbachia symbionts in sperm cysts. $J$. Invert. Pathol., 61, 226-230.
DE BOER, R. 1982. Nucleo-cytoplasmic interactions causing partial female sterility in the spider mite Tetranychus urticae Koch (Acari: Tetranychidae). Genetica, 58, 17-22.

DE BOER, R. 1983. Nucleo-cytoplasmic interactions causing partial female sterility in the spider mite Tetranychus urticae Koch (Acari: Tetranychidae) II. Genetica, 61, 107-111.

EBBERT, M. A. 1993. Endosymbiotic sex ratio distorters in insects and mites. In: Wrensh, D. L. and Ebbert, M. A. (eds) Evolution and Diversity of Sex Ratio in Insects and Mites, pp. 150-191. Chapman and Hall, New York.

EHRMAN, L. 1983. Endosymbiosis. In: Futuyma, D. J. and Slatkin, M. (eds) Coevolution, pp. 128-136. Sinauer Associates, Sunderland, MA.

FRY, J. D. 1989. Nuclear-nuclear and nuclear-cytoplasmic interactions contribute to the reproductive incompatibility between two strains of the twospotted spider mite. Entomologia exp. appl., 50, 97-100.

GOTOH, T. AND TAKAYAMA, K. 1992. Developmental characteristics, genetic compatibility and esterase zymograms in three strains of the hawthorn spider mite, Tetranychus viennensis Zacher (Acari: Tetranychidae). J. Acarol. Soc. Jap., 1, 45-60.

GOTOH, T., BRUIN, J., SABELIS, M. W. AND MENKEN, S. B. J. 1993. Host race formation in Tetranychus urticae: genetic differentiation, host plant preference, and mate choice in a tomato and a cucumber strain. Entomologia exp. appl., 68, 171-178.

HOFFMANN, A. A. 1988. Partial cytoplasmic incompatibility between two Australian populations of Drosophila melanogaster. Entomologia exp. appl., 48, 61-67.

HOFFMANN, A. A. AND TURELLI, M. 1988. Unidirectional incompatibility in Drosophila simulans: inheritance, geographic variation and fitness effects. Genetics, 119, 435-444.

HOFFMANN, A. A., TURELLI, M. AND SimMONS, G. M. 1986. Unidirectional incompatibility between populations of Drosophila simulans. Evolution, 40, 692-701. 
HSIAO, T. H. AND HSIAO, C. 1985. Hybridization and cytoplasmic incompatibility among alfalfa weevil strains. Entomologia exp. appl., 37, 155-159.

KUSHNIR, S., BABIYCHUK, E., BANNIKOVA, M., MOMOT, V., KOMARNITSKY, 1., CHEREP, N. AND GLEBA, Y. 1991. Nucleocytoplasmic incompatibility in cybrid plants possessing an Atropa genome and a Nicotiana plastome. Mol. Gen. Genet., 225, 225-230.

LAVEN, H. 1967. Speciation and evolution in Culex pipiens. In: Wright, J. W. and Pal, R. (eds) Genetics of Insect Vectors of Disease, pp. 251-275. Elsevier, Amsterdam.

NODA, H. 1984. Cytoplasmic incompatibility in a rice planthopper. J. Hered., 75, 345-348.

OLIVER, C. G. 1979. Genetic differentiation and hybrid viability within and between some Lepidoptera species. Am. Nat., 114, 681-694.

OVERMEER, W. P. J. AND VAN ZON, A. Q. 1976. Partial reproductive incompatibility between populations of spider mites (Acarina: Tetranychidae). Entomologia exp. appl., 20, 225-236.

RICHARDSON, P. M., HOLMES, W. P. AND SAUL, G. B., Il. 1987. The effect of tetracycline on nonreciprocal cross incompatibility in Mormoniella $[=$ Nasonia $]$ vitripennis. J. Invert. Pathol., 50, 176-183.

ROUSSET, F. AND RAYMOND, M. 1991. Cytoplasmic incompatibi- lity in insects: why sterilize females? Trends Ecol. Evol., 6, 54-57.

STEVENS, L. 1989. Environmental factors affecting reproductive incompatibility in flour beetles, genus Tribolium. J. Invert. Pathol., 53, 78-84.

STEVENS, L. AND WADE, M. J. 1990. Cytoplasmically inherited reproductive incompatibility in Tribolium flour beetles: the rate of spread and effect on population size. Genetics, 124, 367-372.

STEVENS, L. AND WICKLOW, D. T. 1992. Multispecies interactions affect cytoplasmic incompatibility in Tribolium flour beetles. Am. Nat., 140, 642-653.

THOMPSON, J. N. 1987. Symbiont-induced speciation. Biol. J. Linn. Soc., 32, 385-393.

TORIYAMA, K., TSUNEWAKI, K., NONAKA, S. AND SHIMADA, T. 1993. A breeding scheme proposed for hybrid wheat utilizing male sterility induced by the interaction between an $\mathrm{S}^{\mathrm{V}}$ type cytoplasm and a 1BL-1RS chromosome. Jap. J. Breeding, 43, 517-524.

TRPIS, M., PERRONE, J. B., REISSIG, M. AND PARKER, K. L. 1981. Control of cytoplasmic incompatibility in the Aedes scutellaris complex. J. Hered., 72, 313-317.

WADE, M. J. AND STEVENS, L. 1985. Microorganism mediated reproductive isolation in flour beetles (genus Tribolium). Science, 227, 527-528. 